\title{
Value of Wildland Habitat for Supplying Pollination Services to Californian Agriculture
}

\section{By Rebecca Chaplin-Kramer, Karin Tuxen-Bettman, and Claire Kremen}

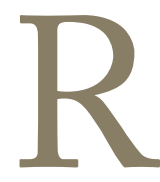

angelands can provide an important ecosystem service to adjacent agricultural fields by providing foraging and nesting habitat that supports populations of naturally occurring crop pollinators, chiefly bee species. ${ }^{1}$ Rangeland habitats such as grasslands, meadows, savannah, and shrublands support diverse bee communities due to the wide variety of nesting habitats they supply. Such habitats include undisturbed ground, cavities in the ground and trees, and hollow-stemmed grasses and reeds that are suitable for species of ground-nesting, wood- and cavity-nesting, and stem-nesting bees, respectively. ${ }^{2}$ Similarly, rangeland habitats often provide a diverse array of flowering forbs, shrubs, and trees that furnish successive blooms, supporting the needs of multiple bee species across their flight seasons. ${ }^{3}$ These bee populations and communities are then available to provide crop pollination in adjacent agricultural fields. ${ }^{4}$ Our paper outlines a method for quantifying the value of pollination services supplied by wild bee communities based on the area of nearby wildland habitats, ${ }^{1}$ chiefly rangelands, to pollinator-dependent crops in California, one of the largest agricultural economies in the world. ${ }^{5}$

\section{The Role of Pollinators in Agricultural Systems}

Pollination services are critically important to human health and well-being, due to the large number of crop species $(75 \%)$ that depend on animal pollinators to produce fruits or seeds (either partially or completely ${ }^{6}$ ) and the essential nutrients supplied by these crop species (e.g., globally, > 90\% of vitamins $\mathrm{A}$ and $\mathrm{C}$ are derived from pollinator-dependent crops). Approximately $35 \%$ of the total biomass of crop production depends on animal pollinators. ${ }^{6}$ Worldwide, pollination services, including those provided by managed bees imported to crop fields and those freely provided by wild bees, are valued at $€ 153$ billion per year (approximately $\$ 216$ billion per year), 9.5\% of annual global crop value. ${ }^{7}$

\section{Managed Pollinators}

Around the world, modern "industrialized" agricultural systems rely extensively on a single, managed, pollinator species, the honeybee (Apis mellifera), to provide crop pollination. ${ }^{8}$ Large monoculture farms of pollinator-dependent species, such as almond, melon, blueberry, and apple, create a huge demand for pollinators during a short time interval, often overwhelming the capacity of naturally occurring pollinator species to provide these services. At the same time, such farms often have reduced abundances of wild bee species, ${ }^{1}$ possibly due to the lack of alternative floral resources other than the mass-flowering crop, ${ }^{9}$ and/or the lack of nest sites ${ }^{10}$ and frequent use of pesticides. ${ }^{10,11}$ Consequently, growers must import managed honeybees during crop bloom, ${ }^{1}$ treating pollination as an input much like fertilization, irrigation, or pest control.

Reliance of growers on honeybees for crop pollination increases grower vulnerability to shortages in honeybee supply. In the United States, the number of honeybee colonies has declined steadily since the 1940 s; ${ }^{12}$ high annual rates of colony loss have also occurred in many regions of North America, Europe, the Middle East, and Asia since approximately $2005,{ }^{13}$ probably due to synergistic effects of viral and parasitic diseases, malnutrition, loss of genetic diversity, and pesticide exposure. ${ }^{14}$ The reduced supply of honeybees in the United States has increased the cost of honeybee rentals, ${ }^{15}$ as well as the uncertainty and difficulty of obtaining this critical farming input. ${ }^{12}$ Growers that receive some pollination services from wild bees thus enjoy an economic advantage. ${ }^{16}$

\section{Wild Pollinators}

Wild pollinators are known to supply sufficient pollination services for fruit set and/or seed set for pollinator-dependent crops, under environmental conditions that support diverse and abundant pollinator communities. ${ }^{1,17,18}$ Diverse pollinator 
communities provide greater magnitude and temporal stability of pollination services through various mechanisms, including complementarity of foraging behavior in space and/or time and varied responses of different species to changing environmental conditions. ${ }^{19}$ Both diversity and abundance of wild pollinator communities are also known in some circumstances to enhance the pollination efficiency of managed honeybees through alteration of honeybee foraging behavior. ${ }^{20}$ Healthy communities of wild bees could provide growers with an "insurance policy" for pollination services against honeybee losses. ${ }^{18,19}$

A quantitative synthesis across a wide variety of crops and biomes showed that crop-visiting wild bees are most abundant and diverse near natural or seminatural habitat, with an exponential decline of diversity and abundance as distance from natural habitat increases. ${ }^{21}$ Relevant habitats included meadow, shrubland, savannah woodland, seminatural woodland, and tropical and temperate forests. In addition, specific studies have found a positive relationship between the diversity and abundance of bees and the pollination services provided, as the proportional area of natural habitat increases. ${ }^{1,17}$ Natural habitat most likely promotes the diversity and abundance of wild bee pollinators on croplands by providing both nesting sites and alternative floral resources when crops are not blooming. ${ }^{22}$

\section{The Value of Pollination Services Provided by Wild Bees}

While the services provided by wild bees are valuable, only a few of the studies measuring values of pollination service have distinguished between the values flowing from wild versus managed bees. ${ }^{8}$ For the United States, pollination services provided by wild bees were estimated at $\$ 3.07$ billion (in 2003 dollars), representing $15.3 \%$ of the total pollination service value. ${ }^{23}$ This calculation assumes a fixed ratio of wild pollinators to honeybees across all landscapes. In contrast, studies that calculated values based on the observed abundances of wild pollinators obtained much higher values and proportions of pollination services attributable to wild pollinators. For example, in New Jersey and Pennsylvania, wild bees provided $62 \pm 5 \%$ of the total value of pollination services to watermelon $\left(\$ 9.95\right.$ million $\left.^{16}\right)$ due to favorable environmental conditions that promote wild bee abundance in these regions. ${ }^{18}$ Even fewer studies have related the value of pollination services to the occurrence of natural habitat as a primary determinant of bee community abundance, diversity, and pollination function. In Indonesia, where the increase in coffee production from animal-mediated pollination is due entirely to wild bees, ${ }^{24}$ the increase in the value of coffee production due to the presence of natural habitat was estimated at $€ 46 /$ ha (approximately $\$ 26$ per acre), and the value of coffee production was projected to decline by $0.3-13.8 \%$ as natural habitat cover decreased under differing scenarios of land-use change over a 20-year period. ${ }^{25}$ In Canada, Morandin and Winston estimated that canola farmers could return up to $30 \%$ of their fields to forb-filled meadows without losing value, since canola yields increased with pollinator abundance and diversity, which was strongly related to the proportional area of meadowlands. ${ }^{17}$ While these spatially explicit studies have been limited in scope to one crop, studies with broader scope $e^{23}$ have not been spatially explicit. This study is the first to integrate spatial information into a large-scale, multicrop database.

Many economic valuation studies on pollination have been conducted without considering the ecology of the system: the reliance of the pollinators on off-farm habitat for floral resources or nesting and overwintering sites or the pollinators' foraging range. In the example that follows, we explore a method of estimating the economic value of wild bee pollination services for Californian agriculture based on the amount and location of natural habitats relative to California's agricultural production areas. We used results from a field study that established the relationship between natural habitat and wild pollination services in California's Central Valley, ${ }^{1}$ and we extrapolated this relationship to other crops and agricultural landscapes in California using spatial landcover data to generate both a statewide estimate and a map of this ecosystem service. While such an extrapolation makes a number of assumptions, and while results must be interpreted with caution, it is a first step toward integrating ecological data into a spatial model for economic valuation. We present these results as a case-study of spatially explicit ecological/economic valuation, while recognizing the limitations of the current data and identifying improvements that could be made with the addition of further data.

\section{Case Study: Value of Wild Bee Pollination Services to California Agriculture}

We estimated in four steps the value of wild bee pollination in California using ecological data. First, we classified California crops according to their dependence on animal pollinators and multiplied this by commodity economic data to obtain the total value of pollination service $\left(\mathrm{PS}_{\mathrm{T}}\right)$ for each crop by county. ${ }^{23}$ Second, we selected land cover types capable of providing habitat for wild pollinator species, creating a geospatial dataset of pollinator-relevant natural and seminatural habitats. Third, using a pre-established relationship between natural habitat and the proportion of pollination needs met, we generated another geospatial dataset translating pollinator-relevant habitat surrounding cropland to a pollination services index. Finally, we calculated the pollination service value from wild pollinators by multiplying the pollination received (from Step 3) by the total value of pollination to the crops (from Step 1).

\section{Step 1: Calculating $P S_{T}$ to Crops in California}

Klein et al. ${ }^{6}$ categorized globally produced crop species into five categories based on the reduction of fruit or seed set in the absence of animal pollinators: "Essential" (>90\% yield reduction without pollinators), "Great" (40-90\% reduction), 
"Modest" (10-40\% reduction), "Little" ( $<10 \%$ reduction), and "No increase" (no change without pollinators). We used this information to classify the 130 crops grown in California according to their pollination dependence.

We obtained commodity-value data from the USDA National Agriculture Statistics Service's County Agricultural Commissioner's Data for 2007. ${ }^{26}$ Each county reports the acreage, yield, sales price, and value (price $\times$ yield) of each crop planted. We multiplied the value of each crop in each county by its amount of pollination dependence to estimate the value of pollination services for each crop in each county $\left(\mathrm{PS}_{\text {crop }}\right)$. Because the Klein et al. ${ }^{6}$ data indicated a range of yield reduction in the absence of pollination, we estimated a lower and upper bound for PS crop. . These upper and lower bounds for $\mathrm{PS}_{\text {crop }}$ were each then summed for all crops in a given county to provide a total countywide estimate of the upper- and lower-bound values of pollination services $\left(\mathrm{PS}_{\text {Tcounty }}\right)$.

The values for $\mathrm{PS}_{\text {Tcounty }}$ could also be summed across all counties to give a statewide estimate of $\mathrm{PS}_{\mathrm{T}}$. This value represents the total potential value of pollination to California agriculture if pollination needs are met by any pollinator (wild or managed honeybee stocks), for comparison against the value of pollination services from wild pollinators $\left(\mathrm{PS}_{\mathrm{W}}\right)$, as described below.

Some crops that were lumped into broader unspecified groups by the USDA (such as "seed-unspecified," "fruit and vinecrop-unspecified," "row crops-unspecified," etc.) could not be classified according to pollinator dependence, and these were omitted from the analysis. These crops represent a value of $\$ 973.38$ million (3\% of the total economic value of nonanimal crops in California). We did not include animal products (worth an additional $\$ 13.5$ billion per year) or animal-related crops (i.e., pasture, silage, or hay, together worth $\$ 2.1$ billion per year) in our estimates of agricultural value, although these products may rely on pollinator-dependent forage such as alfalfa.

\section{Step 2: Selecting Pollinator-Relevant Habitat}

We used the national LANDFIRE Existing Vegetation Type (EVT) dataset to create our pollinator-relevant natural habitat map. The LANDFIRE EVT data product $(30-\mathrm{m}$ resolution) was developed using Landsat imagery (20002002), biophysical gradient data, and a classification and regression tree (CART)-based predictive modeling approach to assign NatureServe's Ecological Systems vegetation types ${ }^{27}$ to each $30-\mathrm{m}$ pixel. ${ }^{28}$

We inspected the 144 vegetation types of NatureServe's Ecological Systems that fell within $2.4 \mathrm{~km}$ of any agricultural land parcel in this dataset, classifying them based on their importance to pollinators (yes $=$ important habitat that would be used by pollinators, no = not important, and maybe $=$ possibly important, see below). We chose a radius distance of $2.4 \mathrm{~km}$ because it was the scale determined by Kremen et al. ${ }^{1}$ to be most predictive of pollination services in a multiscale spatial analysis of the role of natural habitat in explaining pollinator abundance, diversity, and crop pollination services on farm sites in Yolo County, California. Pollinatorrelevance was determined for each vegetation type based on the presence of plant species attractive to pollinators and cover criteria, as described in the NatureServe documentation that accompanies the legend for the LANDFIRE dataset. ${ }^{29}$ Plant species that would be used by pollinators for floral resources were identified using lists provided by the Xerces Society, ${ }^{\mathrm{i}}$ the USDA's Agricultural Research Service, ${ }^{\mathrm{ii}}$ and relevant plant-pollinator interaction data from California natural habitats, ${ }^{30}$ and they are listed in Supplemental Table 1 (see supplemental materials online at http://dx.doi.org/ 10.2111/ RANGELANDS-D-11-00002.s1).

For shrubland and herbaceous vegetation types, if the vegetation type contained two or more plant species providing floral resources to pollinators, it was included as relevant pollinator habitat ("yes"). For forest and woodland vegetation types, we utilized data on canopy cover from the LANDFIRE Existing Vegetation Cover (EVC) dataset ${ }^{28}$ as an additional variable to determine habitat suitability for pollinators. We considered forest and woodland habitats, when listed as containing pollinator-relevant plants, to be unsuitable as pollinator habitat when occurring in dense stands (>60\% canopy closure, defined by LANDFIRE as "closed" or "dense"), because dense forests stands provide relatively few floral resources in their understory and have cooler, darker microclimates less favorable to pollinator activity. We considered such habitats to be suitable when occurring with an open canopy ( $<60 \%$ canopy closure). When species information was incomplete for a vegetation type, or if only one pollinator-relevant plant species was present, we assigned the vegetation type to a "maybe" category, which we included or excluded to determine the sensitivity of the analysis to uncertainty in pollinator habitat. There were 16 vegetation types in the "maybe" category, accounting for $14,000 \mathrm{~km}^{2}$ (5,400 square miles), or approximately 3-4\% of the entire California area.

The LANDFIRE land cover map was converted from existing vegetation types to a binary grid (relevant pollinator habitat $=1$ and irrelevant habitat $=0$ ), using ESRI ArcGIS software. ${ }^{31}$ Two maps were generated: a "yes" map that only included habitat in the "yes" category as relevant pollinator habitat, and a "yes/maybe" map that included both the "yes" and "maybe" categories as relevant pollinator habitat. Only natural habitat (which in our definition includes all unmanaged vegetation types, even those containing invasive species) was considered when creating this map of relevant pollinator habitat. We did not consider the role of farmlands or residential areas, even though such habitats also provide habitat for bees,, 18 because our goal was to quantify the ecosystem service of pollination provided by natural and seminatural habitats.

\footnotetext{
Available at: http://www.xerces.org/Pollinator_Insect_Conservation/ generalplantsforbees.htm.
}

ii Available at: http://www.ars.usda.gov/Research/docs.htm?docid=12052. 
Step 3: Estimating the Pollination Services Index for Wild Pollinators

Using an empirical relationship between natural habitat and the proportion of pollination needs met, ${ }^{1}$ we generated another set of maps translating pollinator-relevant habitat surrounding cropland to a pollination services index (PSI). We calculated the proportion of relevant natural habitat within a $2.4-\mathrm{km}$ radius of each agricultural pixel, with a circular moving window, using ESRI ArcGIS software. ${ }^{31} \mathrm{We}$ then used this proportion in the following equation to determine an index of pollination services provided by wild pollinators.

PSI $=0.001 \times e^{\wedge[5.3222964+(3.7181972 \times \text { proportion of pollinator habitat })]}$

The equation was based on the observed empirical relationship between the proportion of natural habitat and pollen deposition (a measure of pollination services) from wild pollinators on watermelon, at 22 fields situated along a spatial gradient in Yolo County, California, from farms surrounded by natural habitat to isolated farms. ${ }^{1 \text { (Fig.4) }}$ Watermelon is a pollinator-dependent crop in the "Essential" category. ${ }^{6}$ Each flower requires multiple visits by bees to receive enough pollen (approximately 1,000 grains) to set a fruit. ${ }^{32}$ The original empirical relationship modeled pollen deposition, ${ }^{1}$ but it was modified here (by multiplying by 0.001 ) to model the sufficiency of pollination services. In extrapolating to other crops, we reasoned that watermelon serves as a conservative indicator for the sufficiency of pollination services. Because watermelon has relatively high demands both for pollen deposition and number of visits to achieve fruit set, when watermelon receives sufficient services from wild bees, we might expect that other less-demanding crops do also. In addition, watermelon is a good indicator crop because it attracts a large number of bee species across a range of sizes and morphologies, many of which visit other crops. ${ }^{1,19}$

This equation was applied to the entire statewide dataset, first for all relevant habitat ("yes") and then for all relevant and possibly relevant ("yes/maybe") habitat. When the formula produced PSI $>1$, we capped the values at 1.0, since pollination services $>100 \%$ of pollination needs do not provide additional value.

\section{Step 4: Calculating Value of $P S_{W}$}

We calculated the value from $\mathrm{PS}_{\mathrm{W}}$ for each agricultural pixel $i$ by multiplying the PSI received by that pixel by the total value of pollination to the crops in that pixel. To obtain the total value of pollination to crops in a given pixel, we measured the total agricultural area in each county, as designated in the vegetation classes of the LANDFIRE EVT dataset. (The LANDFIRE estimate was used rather than the Agricultural Commissioner's data to maintain consistency with the rest of our spatial analysis; comparison revealed that the two datasets were similar within 5\%.) We converted the upper- and lower-bound estimates of $\mathrm{PS}_{\text {Tcounty }}$ to $\mathrm{PS}_{\mathrm{T} \text { county }}$ per pixel by dividing by the number of pixels of agricultural land in each county. We then multiplied $\mathrm{PS}_{\text {Tcounty }}$ per pixel by the PSI (maximum: 1.0) in that pixel to calculate the value of pollination service provided by wild pollinators from natural habitat at each pixel $\left(\mathrm{PS}_{\mathrm{W}_{i}}\right)$.

$$
\mathrm{PS}_{\mathrm{W} i}=\mathrm{PSI}_{i} \times \mathrm{PS}_{\text {Tcounty }} / \text { pixel }
$$

This generated four maps of $\mathrm{PS}_{\mathrm{W} i}$ (hereafter, scenarios): using upper- and lower-bound estimates of $\mathrm{PS}_{\mathrm{T}}$ crossed against relevant habitat for both the "yes" and "yes/maybe" maps of relevant pollinator habitat. We calculated summary statistics for each county and for the State of California based on each of the four scenarios, using zonal statistics in ESRI ArcGIS software ${ }^{31}$ to obtain the countywide and statewide values of annual ecosystem service value of wild pollinators to California agriculture.

\section{Case-Study Findings: The Value of Pollination and Pollinators}

The total crop value of California agriculture (not including animal products or pasture) is over $\$ 29$ billion per year (10\% of US total value ${ }^{26}$ ). Broken down into the pollinatordependent categories defined by Klein et al., ${ }^{6}$ the "Essential" category makes up $1.3 \%$ of that total value; "Great" makes up 17.5\%; "Modest" makes up 8.7\%; "Little" makes up 12.3\%; and "No increase" makes up 56.8\% (unspecified crops that could not be categorized comprising the remaining 3.3\%; Fig. 1, Supplemental Table 2-online at http://dx.doi.org/ 10.2111/ RANGELANDS-D-11-00002.s1). Together, crops in the first four categories (hereafter "pollinator-dependent crops") were worth $\$ 11.7$ billion in 2007, occupying over 2.5 million acres (37\%) of nonpasture agricultural land.

$\mathrm{PS}_{\mathrm{T}}$ (managed plus wild pollinators) for the state of California is \$2.7-6.3 billion per year based on the lower to upper bounds of dependency values, ${ }^{6}$ which comprises $23-54 \%$ of the total value of pollinator-dependent crops (Fig. 2). Pollination services to "Essential" crops account for 6.4-13.6\% of the $\mathrm{PS}_{\mathrm{T}}$; "Great" crops account for 72.6-76.9\%; "Modest" crops account for 9.5-15.8\%; and "Little" crops account for $0-5.2 \%$. The counties with the highest $\mathrm{PS}_{\mathrm{T}}$ include Fresno, Kern, and Stanislaus (Supplemental Table 3-online at http://dx.doi.org/10.2111/ RANGELANDS-D-11-00002. s1), due primarily to the large acreage of crops grown there but also the type of crops. Specifically, Stanislaus ranks seventh in total crop acreage compared to Fresno (ranked first) and Kern (ranked second), but has a larger proportion of "Great" crops (i.e., almonds and stone fruit) compared to other crops. When considering mean $\mathrm{PS}_{\text {Tcounty }}$ per pixel of agricultural land within each county, the rankings shift substantially. Santa Cruz, San Diego, and Ventura counties enter the top ranks, partially due to the high proportion of "Great" crops (e.g., apple and avocado) grown there. Santa Cruz and Ventura counties also have high ratios of crop 


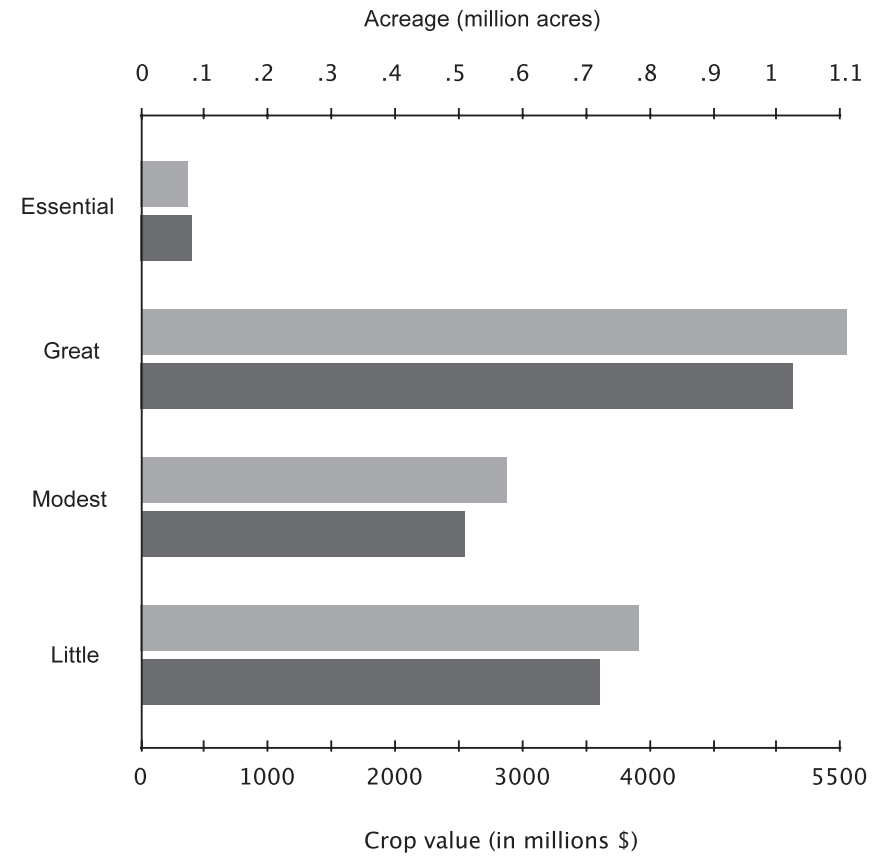

Figure 1. Crop values (darker bars) and harvested acreages (light bars) of pollinator-dependent crops in California, based on the categories defined by Klein et al. ${ }^{6}$

value to acreage (the second and fifth highest in the state, respectively).

The value of $\mathrm{PS}_{\mathrm{W}}$ to California agriculture is between $\$ 937$ million and $\$ 2.4$ billion per year (Table 1). Fresno and Kern remain in the top three counties for $\mathrm{PS}_{\mathrm{W}}$, but they are topped by Tulare for both the high- and low-range estimates (Supplemental Table 3). Tulare also ranks highly on a per pixel basis, for both maximum and minimum values of $\mathrm{PS}_{\mathrm{W} i}$ (Fig. 3, Supplemental Table 3), along with Santa Cruz, San Diego, Orange, and Yuba counties. While $\mathrm{PS}_{\mathrm{W} i}$ for Santa Cruz and San Diego are likely driven by the crops' pollination dependency and value (as noted above, both of these ranked highly on $\mathrm{PS}_{\mathrm{Tcounty}}$ per pixel), Tulare and Yuba have high PSI scores and thus high $\mathrm{PS}_{\mathrm{T}}$ per pixel due to the abundance of pollinator habitat grown in the vicinity of agricultural areas. Level of pollinator-dependence was a 100-fold greater source of uncertainty than the designation of "pollinator-relevant" habitat (Table 1 , around $\$ 1.5$ billion for the difference between the upper- and lower-bound pollinator-dependence estimates vs. between $\$ 6$ million and $\$ 17$ million for the difference between the "yes" and "yes-maybe" cases of pollinator-relevant habitat).

Our calculation for $\mathrm{PS}_{\mathrm{T}}$ (managed plus wild bees) was 9-21\% of the total value of (nonanimal) crops produced in California, which at the upper range is higher than the global estimate $\left(9.5 \%{ }^{7}\right)$, due to the relatively large acreages and high values of pollinator-dependent crops grown in the state. Our goal was to partition this total pollination service value into the values attributable to managed and wild bees; it is the wild bee contribution $\left(\mathrm{PS}_{\mathrm{w}}\right)$ that constitutes the ecosystem service derived from nature. ${ }^{8,22}$ According to our estimate, the proportion of total pollination services provided

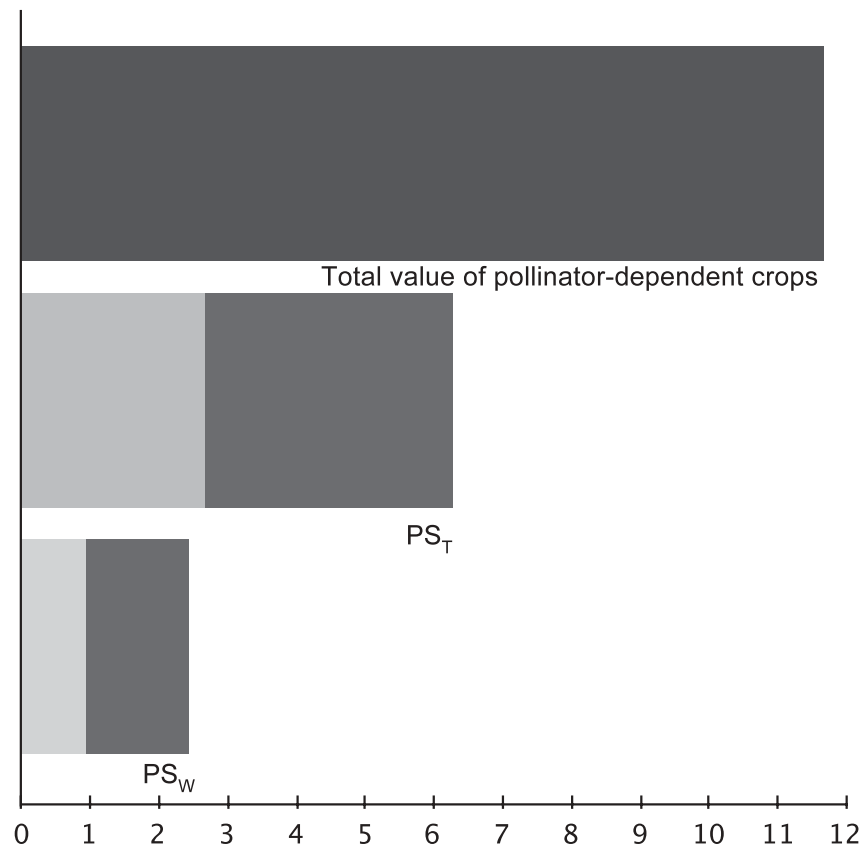

Value (billion \$2007)

Figure 2. Value of pollinator-dependent crops, value of pollination services ( $P S_{\mathrm{T}}$, wild and managed), and value of pollination services from wild pollinators $\left(\mathrm{PS}_{\mathrm{w}}\right)$ for California. The light bars show lower-bound estimates and the darker bars show the upper-bound estimates for $\mathrm{PS}_{T}$ and $\mathrm{PS}_{\mathrm{w}}$.

by wild bees in the state of California was 35-39\%, substantially higher than Losey and Vaughan's ${ }^{23}$ estimate of $15.3 \%$ for the United States, which assumed a constant ratio of wild to managed bees. In contrast, our spatially explicit estimation method utilized the empirically derived loglinear relationship between wild bee pollination services and the surrounding proportion of natural habitat ${ }^{1}$ and is both more accurate and directly tied to the landscape composition of natural habitats surrounding agricultural areas.

\section{Case-Study Caveats and Limitations}

Economic values of pollination services vary by orders of magnitude depending on the calculation method used (proportional production value or replacement cost methods ${ }^{8}$ ) and whether factors such as price elasticity and variable costs are included. ${ }^{7,16}$ Our goal was to incorporate an additional level of ecological realism by utilizing field and landcover

Table 1. The four scenarios for pollination service value from wild pollinators $\left(\mathbf{P S}_{\mathrm{w}}\right.$ ), in millions of 2007 dollars

\begin{tabular}{|l|c|c|c|}
\hline Bound & $\begin{array}{c}\text { Dependency } \\
\text { estimate }\end{array}$ & $\begin{array}{c}\text { Bee-relevant } \\
\text { habitat }\end{array}$ & PS $_{\mathbf{w}}$ (millions) \\
\hline Lowest & Lower & Yes & $\$ 937.30$ \\
\hline Mid-low & Lower & Yes-maybe & $\$ 943.74$ \\
\hline Mid-high & Upper & Yes & $\$ 2,410.79$ \\
\hline Highest & Upper & Yes-maybe & $\$ 2,427.15$ \\
\hline
\end{tabular}



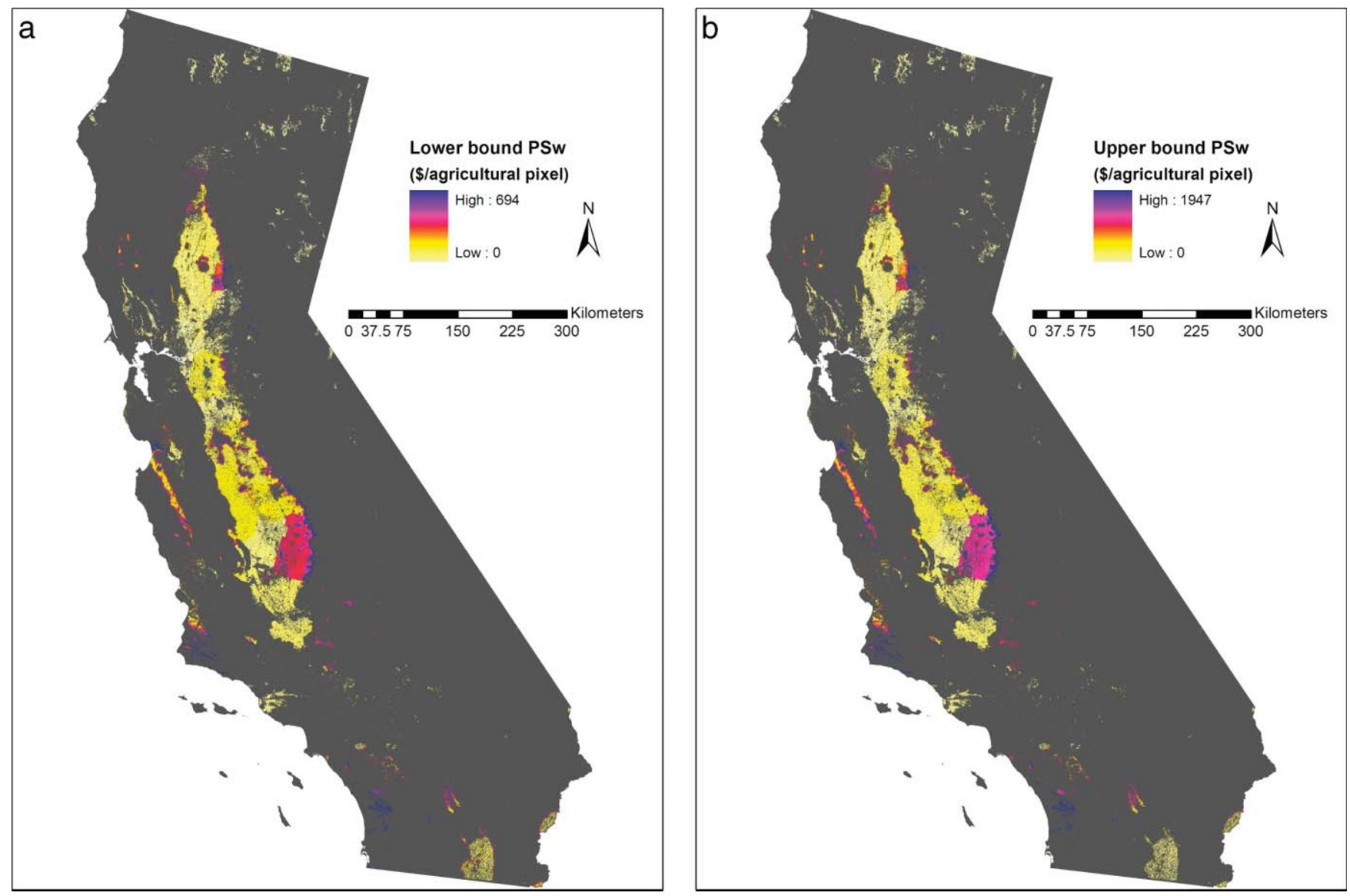

Figure 3. Map of pollination service value provided by wild pollinators per pixel $\left(P S_{w_{i}}\right)$ for the (a) lowest (lower-bound dependence estimate with only "yes" pollinator habitat) and (b) highest (upper-bound dependence estimate with "yes" and "yes-maybe" pollinator habitats) scenarios. The main difference between scenarios is not where areas of high value occur, but the magnitude of that value (shown on scales inset at right of map). Values are shown in 2007 dollars per pixel of agricultural land. The large hotspot in the southeastern portion of the map is Tulare County.

data to generate a spatially explicit valuation of pollination services from wild bees. We used a single valuation method, the proportional dependence method, ${ }^{8,23}$ that was feasible to apply to our large dataset. However, this method overestimates total values of pollination services because it ignores farmer behavior, which would tend to abate production losses due to absolute loss or increased costs of pollination services. ${ }^{33}$ An improvement on the proportional dependence method subtracts the variable costs of production (e.g., harvesting costs) from the total crop value. These costs can vary depending on the level of pollination services and crop yield. ${ }^{16}$ We did not attempt to make this correction because obtaining variable cost data for 85 crops over such a large geographic area was not feasible, and because the relative value of wild versus managed pollinators should not change due to the inclusion of variable costs (although relative values would change if managed pollinators are considered the primary pollinators and wild the secondary pollinators compared to vice versa ${ }^{16}$ ).

While in general, use of the production value method overestimates values of pollination services, sources of uncertainty specific to our study tend to underestimate pollination services.
We underestimated total pollination-service value because in some cases the type of crop was unspecified or was not fully specified. If the unspecified crops, whose pollination dependencies cannot be determined, followed a similar distribution to the specific crops, we would have underestimated the total value of pollination in California agriculture by $\$ 91.8-$ 216.1 million (3.4\% of the lower versus upper estimate, respectively). If sunflower crops were grown exclusively for hybrid seed production, their dependence on pollinators would change from "Modest" to "Essential", ${ }^{20}$ increasing the $\mathrm{PS}_{\mathrm{T}}$ by $\$ 22.3-29.3$ million (0.4-1.1\%). Finally, we did not consider the value of pollination to meat or dairy production, despite the fact that pollinators are important to forage crops such as alfalfa.

We also likely underestimated the value of wild pollination services for California because our indicator crop, watermelon, requires a greater number of pollinator visits to produce a marketable fruit than many other crops. ${ }^{32}$ Thus other crops may be sufficiently pollinated with fewer pollinators and less surrounding natural habitat. While the exact nature of the relationship between natural habitat and wild bee abundance, diversity, and pollination services may change 


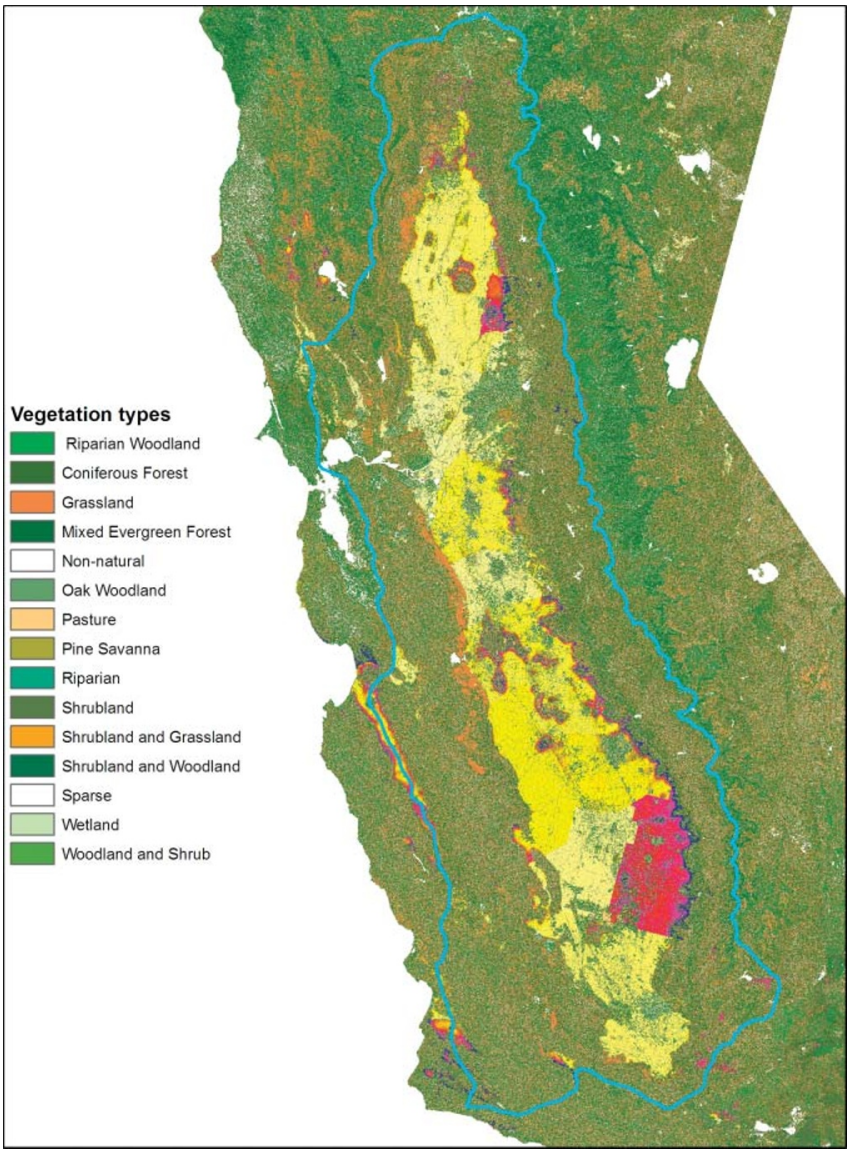

Figure 4. Map of pollination service value provided by wild pollinators $\left(P S_{w}\right)$ overlaid on coarse categories of vegetation types. Grasslands are shown in orange, and they border much of the agricultural area receiving pollination services. Different types of forest are shown in various shades of green. Values of pollination services provided by wild pollinators $\left(\mathrm{PS}_{\mathrm{wi}_{i}}\right)$ are shown as in Figure 3. The blue boundary shows the priority conservation acquisition area for the California Rangeland Conservation Coalition (see http://www.carangeland.org/images/Rangeland_Coalition_ Map.pdf for more detail), which encompasses much of the habitat important to providing pollination services to farmland.

from crop to crop, the positive relationship between natural habitat and wild bee pollination services of watermelon is repeated in our studies of almond (C. Kremen, unpublished data, 2009) and other crops (tomato ${ }^{4}$ and sunflower ${ }^{20}$ ) in California and in a worldwide synthesis. ${ }^{21}$ As more of these relationships are quantified, they could be incorporated into a more detailed analysis than was possible in this study with current data, but this case study represents a first step toward integrating spatially explicit ecological data into economic valuation.

Another source of error that may underestimate the true value of wildlands to pollination services is that we only considered vegetation types as suitable or potentially suitable pollinator habitat if they provided floral resources, but some habitats poor in floral resources may still provide regions suitable for nesting (e.g., the dense forest vegetation that we excluded) and contribute to pollinator abundance. Other models of pollination services can incorporate the value of nesting habitat separately from its value for floral resources. ${ }^{34}$ Since we have not accounted for the nesting value of this vegetation type, we may have underestimated pollinator abundances on nearby farmland. Furthermore, we recognize that different vegetation types will provide greater or lesser value as pollinator habitat depending on the number and type of floral resources they provide. Our analysis simply selects all habitats that may contribute floral resources, without differentiating those that provide many or most of the resources needed to sustain pollinator communities from those providing only a few.

The spatial resolution of the crop data was available only at the county level, which required us to assume homogeneity of crop plantings at the countywide scale (all pixels were ascribed the same "basket" of crop types). At this resolution, hotspots on the pollination services map are typically counties with large areas of crops or small-to-large areas of highvalue crops that receive a large amount of benefit from pollination services, either because the crops they grow are highly dependent on animal pollinators or because they are close to habitat that can meet their pollination needs, or both. Farm-level spatial data on crop plantings would improve the accuracy of the spatial model and the resulting countywide and statewide valuations, as well as the resolution of the map for conservation planning, permitting teasing apart areas that receive high benefit from pollination services due to habitat proximity from those growing high proportions of high value crops.

\section{Conclusions and Applications}

Much of the natural vegetation promoting the ecosystem service of pollination on farmlands is rangeland (Fig. 4). Rangelands have the potential to provide many ecosystem services simultaneously (e.g., forage, pollination services, carbon sequestration, etc.) and identifying these services and what factors contribute to maintaining them will help guide management practices to optimize ecosystem service provision. Therefore, mapping ecosystem services is essential to improving management in order to visualize areas of overlap and the connection between certain habitats. Furthermore, to the extent that the land providing these pollination services is unprotected, a map of pollination service values such as those provided here may provide important guidance for conservation prioritization of rangeland areas. ${ }^{35}$ Despite the limitations of the analysis presented here, it furthers the ecologically grounded and spatially explicit economic valuation of pollination services and provides a methodology upon which future efforts can build. Continuing to integrate ecological, economic, and geospatial data will be necessary for future management of landscapes for the provision of vital ecosystem services such as pollination.

\section{Acknowledgments}

The authors wish to thank Carsten Goff and the LANDFIRE EVT, and the Geospatial Innovation Facility at UC Berkeley 
for the spatial data and facilities to conduct these analyses. We thank Tiffany Shih and Chieko Plotts for their work on the initial stages of data acquisition.

\section{References}

1. Kremen, C., N. M. Williams, R. L. Bugg, J. P. Fay, and R. W. Thorp. 2004. The area requirements of an ecosystem service: crop pollination by native bee communities in California. Ecology Letters 7:1109-1119.

2. Potts, S. G., B. Vulliamy, S. Roberts, C. O'Toole, A. Dafni, G. Ne'Eman, and P. Willmer. 2005. Role of nesting resources in organising diverse bee communities in a Mediterranean landscape. Ecological Entomology 30:78-85.

3. Potts, S. G., B. Vulliamy, A. Dafni, G. Ne'Eman, and P. G. Willmer. 2003. Linking bees and flowers: how do floral communities structure pollinator communities? Ecology 84:26282642 .

4. Greenleaf, S. S., and C. Kremen. 2006. Wild bee species increase tomato production and respond differently to surrounding land use in Northern California. Biological Conservation 133:81-87.

5. Walker, R. A. 2004. The conquest of bread: 150 years of agribusiness in California. New York, NY, USA: The New Press. $382 \mathrm{p}$.

6. Klein, A. M., B. Vaissière, J. H. Cane, I. Steffan-Dewenter, S. A. Cunningham, C. Kremen, and T. Tscharntke. 2007. Importance of crop pollinators in changing landscapes for world crops. Proceedings of the Royal Society of London Series B-Biological Sciences 274:303-313.

7. Gallai, N., J. M. Salles, J. Setetele, and B. E. Vaissiere. 2009. Economic valuation of the vulnerability of world agriculture confronted with pollinator decline. Ecological Economics 68:810821.

8. Allsopp, M. H., W. J. De Lange, and R. Veldtman. 2008. Valuing insect pollination services with cost of replacement. PLOS ONE 3. (9): e3128. doi:10.1371/journal.pone.0003128.

9. Holzschuh, A., I. Steffan-Dewenter, and T. TscharnTKE. 2008. Agricultural landscapes with organic crops support higher pollinator diversity. Oikos 117:354-361.

10. Williams, N. M., E. E. Crone, T. H. Roulston, R. L. Minckley, L. Packer, and S. G. Ротts. 2010. Ecological and life-history traits predict bee species responses to environmental disturbances. Biological Conservation 143:2280-2291.

11. Brittain, C. A., M. Vighi, R. Bommarco, J. Settele, and S. G. Роттs. 2010. Impacts of a pesticide on pollinator species richness at different spatial scales. Basic and Applied Ecology 11:106-115.

12. National Research Council. 2007. Status of pollinators in North America. Volume xiii. Washington, DC, USA: National Academy Press. 326 p.

13. Neumann, P., and N. L. Carreck. 2010. Honey bee colony losses. Journal of Apicultural Research 49:1-6.

i4. Potts, S. G., J. C. Biesmeijer, C. Kremen, P. Neumann, O. Schweiger, and W. E. Kunin. 2010. Global pollinator declines: trends, impacts and drivers. Trends in Ecology $\mathcal{\sigma}^{\circ}$ Evolution 25:345-353.

15. Sumner, D. A., And H. Boriss. 2006. Bee-economics and the leap in pollination fees. Giannini Foundation of Agricultural Economics Update 9:9-11.

16. Winfree, R., And B. J. Gross. 2010. A new method for valuing crop pollination. In: B. Gross. Beneficial bees and pesky pesks [dissertation]. Berkeley, CA, USA: University of California. p. 7-25.

17. Morandin, L. A., and M. L. Winston. 2006. Pollinators provide economic incentive to preserve natural land in agroecosystems. Agriculture Ecosystems E Environment 116:289-292.

18. Winfree, R., and C. Kremen. 2009. Are ecosystem services stabilized by differences among species? A test using crop pollination. Proceedings of the Royal Society B-Biological Sciences 276:229-237.

19. Klein, A. M., C. M. Mueller, P. Hoenn, and C. Kremen. 2009. Understanding the role of species richness for pollination services. In: D. Bunker, A. Hector, M. Loreau, C. Perrings, and S. Naeem [EDs.]. Biodiversity, ecosystem functioning, and human wellbeing: an ecological and economic perspective. New York, NY, USA: Oxford University Press. p. 195-208.

20. Greenleaf, S. S., and C. Kremen. 2006. Wild bees enhance honey bees' pollination of hybrid sunflower. Proceedings of the National Academy of Sciences 103:13890-13895.

21. Ricketts, T. H., J. Regetz, I. Steffan-Dewenter, S. A. Cunningham, C. Kremen, A. Bogdanski, B. GemmillHerren, S. S. Greenleaf, A. M. Klein, M. M. Mayfield, L. A. Morandin, A. Ochieng, and B. F. Viana. 2008. Landscape effects on crop pollination services: are there general patterns? Ecology Letters 11:499-515.

22. Kremen, C., N. M. Williams, M. A. Aizen, B. GemmillHerren, G. Lebuhn, R. Minckley, L. Packer, S. G. Potts, T. Roulston, I. Steffan-Dewenter, D. P. Vazquez, R. Winfree, L. Adams, E. E. Crone, S. S. Greenleaf, T. H. Keitt, A. M. Klein, J. Regetz, and T. H. Ricketts. 2007. Pollination and other ecosystem services produced by mobile organisms: a conceptual framework for the effects of land-use change. Ecology Letters 10:299-314.

23. Losey, J. E., And M. Vaughan. 2006. The economic value of ecological services provided by insects. BioScience 56:311-323.

24. Klein, A. M., I. Steffan-Dewenter, and T. Tscharntke. 2003. Bee pollination and fruit set of Coffea arabica and C-canephora (Rubiaceae). American Journal of Botany 90:153-157.

25. Priess, J. A., M. Mimler, A. M. Klein, S. Schwarze, T. Tscharntke, and I. Steffan-Dewenter. 2007. Linking deforestation scenarios to pollination services and economic returns in coffee agroforestry systems. Ecological Applications 17:407-417.

26. USDA. 2007. Census of agriculture. Table 1. Historical highlights: 2007 and earlier census years. Available at: http://www. agcensus.usda.gov/Publications/2007/Full_Report/Volume_1, Chapter_1_US/index.asp. Accessed 16 September 2010. See also http://www.nass.usda.gov/Statistics_by_State/ California/ Publications/AgComm/.

27. Comer, P., D. Faber-Langendoen, R. Evans, S. Gawler, C. Josse, G. Kittel, S. Menard, M. Pyne, M. Reid, K. Schulz, K. Snow, J. Teague. 2003. Ecological systems of the United States: a working classification of U.S. terrestrial systems. Arlington, VA, USA: NatureServe. 75 p.

28. U.S. Department of Interior, Geological Survey. 2006. The national map LANDFIRE national existing vegetation type layer. (Last updated September 2006.) Available at: http:// gisdata.usgs.net/website/landfire/. Accessed 3 January 2010.

29. NatureServe. 2007. International ecological classification standard: terrestrial ecological systems of the United States. Natural heritage central databases. Arlington, VA, USA: NatureServe. 
30. Williams, N. M., D. Cariveau, R. Winfree, and C. Kremen. 2010. Bees in disturbed habitats use, but do not prefer, alien plants. Basic and Applied Ecology doi:10.1016/j.baae.2010.11.008.

31. [ESRI] Environmental Systems Resource Institute [computer program]. 2009. ArcGIS 9.2. Redlands, CA, USA: ESRI.

32. Stanghellini, M. S., J. T. Ambrose, and J. R. Schultheis. 1997. The effects of honey bee and bumble bee pollination on fruit set and abortion of cucumber and watermelon. American Bee Journal 137:386-391.

33. Muth, M. K., and W. N. Thurman. 1995. Why support the price of honey. Choices 2nd quarter: 19-23.

34. Lonsdorf, E., C. Kremen, T. Ricketts, R. Winfree, N. WilLIAMs, AND S. GreEnleaf. 2009. Modelling pollination services across agricultural landscapes. Annals of Botany 103: 1589-1600.

35. Cameron, D. 2007. Biological prioritization of rangelands: approach and methods. California Rangeland Conservation Coalition. The Nature Conservancy. Available at: http://www. carangeland.org/images/Approach_and_Methods.pdf. Accessed 14 December 2010.
Authors are Postdoctoral Researcher, California Institute for Energy E๐ Environment, University of California-Berkeley, Berkeley, CA 94720, USA, rchaplin@berkeley.edu (ChaplinKramer; with Department of Environmental Science, Policy E。 Management, University of California-Berkeley, Berkeley, CA 94720, USA, while work was conducted); GIS Specialist, Google Earth Outreach, Mountain View, CA 94043, USA (TuxenBettman; with Department of Environmental Science, Policy E。 Management, University of California-Berkeley, Berkeley, CA 94720, USA, while work was conducted); and Associate Professor, Department of Environmental Science, Policy E Management, University of California-Berkeley, Berkeley, CA 94720, USA (Kremen). The UC Berkeley Chancellor's Partnership Fund provided partial support for the GIS analyses. RCK was supported by a Graduate Research Fellowship from the National Science Foundation. 